\title{
ВЗАИМОСВЯЗЬ СВОЙСТВ ТЕМПЕРАМЕНТА И ПРОФЕССИОНАЛЬНОЙ НАПРАВЛЕННОСТИ ЛИЧНОСТИ У КУРСАНТОВ ВОЕННЫХ ИНСТИТУТОВ ВОЙСК НАЦИОНАЛЬНОЙ ГВАРДИИ РОССИЙСКОЙ ФЕДЕРАЦИИ
}

\section{THE RELATIONSHIP OF THE PROPERTIES OF TEMPERAMENT AND PROFESSIONAL ORIENTATION OF PERSONALITY IN THE CADETS OF MILITARY INSTITUTES OF THE NATIONAL GUARD OF THE RUSSIAN FEDERATION}

\section{R. Fakhurdinov}

Summary: The article examines the issue of the relationship between the properties of temperament and the professional orientation of the personality of a cadet. The article highlights the theoretical aspects of the concept of temperament and its main properties. The theoretical aspects of the concept of professional orientation are considered. Some results of an empirical study of the relationship between the properties of temperament and the professional orientation of the personality of cadets are presented.

Keywords: properties of temperament, temperament, orientation, professional orientation, personality, cadet, troops of the National Guard of the Russian Federation.

\author{
Фахурдинов Ренат Равильевич \\ Новосибирский военный институт имени генерала \\ армии И.К.Яковлева войск начиональной гвардии \\ Российской Федерации \\ 2. Новосибирск \\ yul-zhivaeva@yandex.ru
}

Аннотация: В статье рассматривается вопрос взаимосвязи свойств темперамента и профессиональной направленности личности курсантов. Освещаются теоретические аспекты понятия темперамент и его основные свойства. Рассмотрены теоретические аспекты понятия профессиональной направленности. Приводятся результаты эмпирического исследования взаимосвязи свойств темперамента и профессиональной направленности личности курсантов.

Ключевые слова: свойства темперамента, темперамент, направленность, профессиональная направленность, личность, курсант, войска национальной гвардии Российской Федерации.
A ктуальность исследования. В настоящее время не теряют своей актуальности вопросы, касающиеся изучения взаимного влияния особенностей темперамента и профессиональной направленности личности, наблюдаемых у курсантов военных образовательных учреждений войск национальной гвардии РФ. Имеющийся объём исследований, проведённых в этой сфере, всё ещё оставляет многие аспекты проблемы проработанными не до конца. Так, например, не обнаруживается чётко сформулированного и научно обоснованного ответа на вопрос о том, каким образом требуется развивать профессиональную направленность личности, принимая во внимание свойства темперамента, с целью достижения успешной профессиональной деятельности будущих военнослужащих.

По мере углубления научной проработанности понимания темперамента деятели психологии получали всё более ясные и однозначные представления о том, что есть темперамент, каково его значение в процессах, формирующих личность, какие особенности в системе психических феноменов ему присущи. Так, Я. Стреляу го- ворил: «Уже давно было замечено, что люди отличаются друг от друга своим поведением: по-разному выражают свои чувства, неодинаково реагируют на раздражители внешней среды, находятся в разных отношениях с окружающим миром. Так возникла «наука о темпераментах», в которой, хотя она и является одним из старейших разделов психологии, до сих пор нет ни однозначных положений, ни общепринятых решений ее проблем» [12].

Не подлежит сомнению тот факт, что человеческая личность, общий психологический профиль формируются под воздействием особенностей темперамента, присущего индивиду. Именно типом темперамента во многом определяется характерная для каждого индивидуума совокупность личностных особенностей, выделяющая его среди других членов общества. Таким образом, значимость изучения темперамента неоспорима, когда речь заходит о разработке проблематики человеческой индивидуальности.

Темперамент человека представляет собой комплекс специфических свойств психики, которыми в той 
или иной мере определяются поведение, психическая активность, степень выраженности нейротизма, коммуникабельность и многие другие личностные черты [7]. Первым среди учёных термин «темперамент» употребил ещё Гиппократ. Он выдвинул гипотезу о наличии в человеческом организме специфичных нейрогуморальных жидкостей, имеющих ряд отличительных свойств. Согласно предположениям древнегреческого целителя, от свойств этих жидкостей и зависит формирование психического склада индивида.

Позже теория Гиппократа получила продолжение в работах Галена. Древнеримский учёный выделил 4 типа темперамента, базирующихся на преобладании в человеческом организме определённого «жизненного сока». Так, по представлениям Галена, флегматический темперамент присущ людям, в чьём организме преобладает лимфа (слизь, флегма); холерический характерен для людей с преобладанием жёлтой желчи; меланхолический тип темперамента обнаруживается у людей, в чьих организмах в наибольшем объёме обнаруживается чёрная желчь; и, наконец, сангвинический тип - присущ людям с преобладанием крови в организме.

В своих научных работах К.Г. Юнг обозначил два основополагающих свойства человеческого темперамента - экстраверсию и интроверсию [1]. Их суть сводится к следующему: индивиды с экстравертированным типом темперамента в большей мере ориентированы на коммуникацию и взаимодействие с окружением, люди же с интровертированным типом обнаруживают высокую сосредоточенность на собственных внутренних переживаниях. К числу экстравертированных типов темперамента К.Г. Юнг отнёс холерический и сангвинический, к интровертированным - меланхолический и флегматический типы. Впоследствии идея Юнга была продолжена Г. Айзенком, который дал определение ещё одной важной характеристике темперамента - нейротизму. Таким образом, индивидуумы с холерическим типом темперамента были отнесены в группу экстравертов, которым присущ высокий уровень нейротизма; сангвиники - в группу экстравертов, чей нейротизм выражен в умеренной степени; люди с флегматическим типом темперамента были названы интровертами, обладающими низким уровнем нейротизма; меланхоликами же были признаны интровертированные индивидуумы, обладающие высоким уровнем нейротизма. Опросник Г. Айзенка, призванный выявить степени выраженности у респондента экстраверсии и нейротизма, и по сей день является наиболее популярной методикой из всех, что применяются для определения типа темперамента.

Важно понимать, что темперамент не влияет на уровень общих или узких способностей человека. Среди группы индивидов, обладающих одним типом темперамента, могут обнаружиться как талантливые и успешные личности, так и люди, относящиеся к числу слабо одарённых. Аналогично, люди с разными типами темперамента нередко становятся профессионалами в одной сфере деятельности. При этом некоторые особенности, присущие человеку с тем или иным типом темперамента, при удачном стечении обстоятельств могут выступать мощным поддерживающим фактором и облегчать его профессиональную деятельность, способствуя достижению успехов; в противоположном же случае эти особенности превращаются в помеху и препятствие. Если требования деятельности диссонируют с присущими индивиду свойствами темперамента, человек вынужден отдавать предпочтение определённым способам осуществления профессиональной деятельности, не противоречащим его типу темперамента и способствующим преодолению его негативных проявлений [4].

В настоящее время психологи выделяют следующие ведущие характеристики темперамента: сила процессов возбуждения, сила процессов торможения, энергичность, эмоциональность, темп [10].

Сила процессов возбуждения позволяет судить о том, какое время требуется человеку для полноценного включения в деятельность, насколько выраженно он реагирует на стимулы окружающей среды, какую эффективность демонстрирует при осуществлении деятельности.

Силой процессов торможения определяется способность индивида к самоконтролю, скорость подавления возбуждения, терпение, сосредоточенность и концентрация.

Такие свойства темперамента, как эмоциональность, энергичность и темп, традиционно рассматриваются через призму двух аспектов: предметного и социального.

Рассматривая энергичность в предметном контексте, обозначают уровень активности, который демонстрирует человек в процессе обучения. В контексте социальной сферы под энергичностью понимают уровень активности, демонстрируемый человеком при осуществлении коммуникации с окружающими и налаживании социальных связей.

Темп в предметном аспекте - это скорость моторнодвигательных реакций индивида; в социальном контексте - скорость речи, активность жестов и мимики, время, которое требуется для установления взаимопонимания с оппонентом в разговоре.

Эмоциональность - характеристика темперамента, показывающая, эмоции какой силы и выраженности сопровождают переживание человеком тех или иных важных для него событий. Соответственно, в социаль- 
ном контексте эмоциональность определяется силой и выраженностью чувств, проявляемых человеком в межличностных взаимодействиях [6].

Вышеперечисленные характеристики влияют не только на профессиональное самоопределение и избрание человеком предпочитаемой специальности, но и на результаты обучения и работы, достижение успехов в той или иной сфере деятельности. Совокупность свойств темперамента может стать базой для формирования профессиональной направленности будущего специалиста.

Проблеме направленности личности отводится значимое место в психологии личности, так как в неё входит совокупность потребностей мотивационной сферы индивида. Направленность выступает важнейшим психолого-педагогическим фактором, которым определяются воспитание и творческие способности человека; в ней реализуются потребности личности, касающиеся предпочитаемых областей знания, выбора профессии.

Профессиональная направленность характеризуется двумя чертами - содержательной и динамической. Содержание показывает, насколько целостна и развита профессиональная направленность личности; динамика показывает, насколько направленность устойчива и интенсивна, а так же какова её протяжённость во времени.

Направленность личности можно изучать в контексте отношения человека к окружающей его действительности. Согласно В.Н. Мясищеву, направленность есть ничто иное, как совокупность сознательных связей, которые индивидуум выстраивает с разными аспектами реального мира [9].

Направленность несёт в себе интегральную функцию: взаимодействуя друг с другом, её элементы способствуют образованию новых интегративных качеств. Взаимная связь отдельных частей направленности, как целостной системы, настолько выражена, что изменения в одной из них незамедлительно приводят к воздействию на другие, благодаря чему изменяется вся система. Таким образом, динамика системы ценностей оказывает решающее влияние на мотивационную сферу и направленность деятельности индивида [10].

Также выделяют системообразующую роль направленности, заключающуюся в формировании полноты личности и достижении в ней внутренней гармонии. В ряде случаев индивиду сложно осознать необходимость некоторых элементов деятельности, что приводит к прокрастинации и лени, снижает эффективность и качество осуществления действий. Правильным образом воздействуя на направленность личности, можно стимулировать процесс саморазвития.
Целеобразующая функция направленности заключается в обозначении направления становления личности человека, формировании жизненных целей. Когда индивидуум осознанно, преследуя свои интересы и учитывая свои склонности, определяет жизненные цели - он не подвергается воздействию стимулов окружающей среды в той мере, в которой они могут существенно повлиять на его активность. Целеобразование способствует подготовке индивида к квалифицированной трудовой деятельности [5].

Важнейшая функция направленности - избирательная. Посредством неё формируются взгляды индивида и его отношения с окружающим миром, в том числе взгляды на самого себя и отношение к себе самому. Избирательность помогает человеку систематизировать явления и процессы в зависимости от того, какую важность они для него представляют.

Профессиональная направленность выражается в том, какой спектр профессий или же конкретная специальность выступают приоритетными для индивида, какой деятельности он отдаёт предпочтение, рассматривая её как наиболее интересную, привлекательную, подходящую и выгодную для себя [2].

Подростковый возраст становится начальным этапом, на котором развиваются избирательные позитивные взгляды на ту или иную специальность. На формирование отношения к спектру потенциальных видов профессиональной занятости влияет множество факторов, к которым можно отнести мотивы, интересы, предпочтения, способности, социальную среду, характеристики самой специальности (например, простота освоения, престиж и др.). Важными составляющими, формирующими профессиональную направленность индивида, выступают особенности его психофизиологии, такие как состояние здоровья, специфика функционирования нервной системы [3].

Говоря о проблематике профессиональной направленности личности, не стоит выносить за скобки и смежные области - профессионально важные качества, профессиональное самоопределение, профессиональную ориентацию, профессиональную пригодность. К профессионально важным качествам относят комплекс отличительных личностных черт индивида, от которых зависят успех, качество и результативность выбранного им вида деятельности. Профессиональное самоопределение заключается в том, как индивид определяет самого себя касательно уже сформированных в социуме норм, определяющих уровень профессионализма. Профессиональная ориентация - это комплекс предпринимаемых педагогами и обучающимися мер и действий, благодаря которым усваиваются базовые знания о выбранной совокупности профессий, а также разъясняется специфи- 
ка конкретных видов деятельности. Профессиональная пригодность напрямую связана с рядом психических и физиологических особенностей обучающегося, требуемых для успешного освоения избранной им специальности.

Экспериментальной базой нашего исследования послужил Новосибирский военный институт имени генерала армии И.К. Яковлева войск национальной гвардии Российской Федерации. В исследовании приняли участие курсанты с 1 по 4 курс Новосибирского военного института имени генерала армии И.К. Яковлева войск национальной гвардии Российской Федерации. Выборка исследования составила 400 респондентов, в возрасте от 18 до 23 лет.

Методы и методики. На первом, организационном этапе, нами был осуществлён подбор диагностического инструментария для исследования взаимосвязи свойств темперамента и профессиональной направленности личности курсантов. Для проведения эксперимента были выбраны следующие диагностические методики: методика «Опросник свойств темперамента Я. Стреляу» (в русскоязычной адаптации Н.Н. Даниловой и А.Г. Шмелева) и методика профессионального самоопределения Дж. Голланда (Тест-опросник Холланда).

Результаты исследования. Исследование свойств темперамента проводилось при помощи методики «Опросник свойств темперамента Я. Стреляу» (в русскоязычной адаптации Н.Н. Даниловой и А.Г. Шмелева). Проанализирем результаты исследования.

Процессы возбуждения на низком уровне наблюдаются у $9,7 \%$ респондентов, на среднем у 49,6\%, на высоком у $40,7 \%$.

Изучая процессы торможения возможно констатировать, что низкий уровень выявлен у 7,1\% респондентов, средний у 59,3\%, высокий у 33,6\%.

Подвижность нервных процессов представлена следующим образом: низкий уровень обнаружен у 6,2\% респондентов, средний у 68,1\%, высокий у $25,7 \%$.

Анализ уравновешенности личности показывает, что низкий уровень у выявлен у 2,7\%, средний у $56,6 \%$, высокий у 40,7\% респондентов.

Для исследования профессиональной направленности личности нами была использована методика диагностики профессиональной направленности Дж. Холланда.

Так, реалистичный тип личности (р) выявлен у $26 \%$ респондентов; интеллектуальный тип личности (и) - 17\%; социальный тип личности (c) - 23\%; конвенциальный тип личности (к) - 16\%; предприимчивый тип личности (п) 8\%; артистичный тип личности (а) - 11\%.

Реалистичному типу личности свойственна эмоциональная стабильность, ориентация на настоящее. Представители данного типа занимаются конкретными объектами и их практическим использованием: вещами, инструментами, машинами. Отдают предпочтение занятиям требующим моторных навыков, ловкости, конкретности.

Артистичный тип отстраняется от отчетливо структурированных проблем и видов деятельности, предполагающих большую физическую силу. В общении с окружающими опираются на свои непосредственные ощущения, эмоции, интуицию и воображение. Ему присущ сложный взгляд на жизнь, гибкость, независимость суждений. Свойственна несоциальность, оригинальность.

Социальный тип ставит перед собой такие цели и задачи, которые позволяют им установить тесный контакт с окружающей социальной средой. Обладает социальными умениями и нуждается в социальных контактах. Стремятся поучать, воспитывать. Гуманны. Способны приспособиться практически к любым условиям. Стараются держаться в стороне от интеллектуальных проблем. Они активны и решают проблемы, опираясь главным образом на эмоции, чувства и умение общаться.

Конвенциональный тип отдает предпочтение четко структурированной деятельности. Из окружающей его среды он выбирает цели, задачи и ценности, проистекающие из обычаев и обусловленные состоянием общества. Ему характерны серьезность настойчивость, консерватизм, исполнительность. В соответствии с этим его подход к проблемам носит стереотипичный, практический и конкретный характер.

Предприимчивый тип избирает цели, ценности и задачи, позволяющие ему проявить энергию, энтузиазм, импульсивность, доминантность, реализовать любовь к приключенчеству. Ему не по душе занятия, связанные с ручным трудом, а также требующие усидчивости, большой концентрации внимания и интеллектуальных усилий. Предпочитает руководящие роли, в которых может удовлетворять свои потребности в доминантности и признании. Активен, предприимчив.

Интеллектуальный тип ориентирован на умственный труд. Он аналитичен, рационален, независим, оригинален. Преобладают теоретические и в некоторой степени эстетические ценности. Размышления о проблеме он предпочитает занятиям по реализации связанных с ней решений. Ему нравится решать задачи, требующие абстрактного мышления. 
С целью выявления взаимосвязей между изучаемыми характеристиками личности курсантов военного института данные исследования были обработаны нами с помощью программы «STATISTICA - 16.0». Для выявления взаимосвязей между изучаемыми характеристиками мы использовали коэффициент ранговой корреляции Спирмена. Данный метод позволяет определить степень тесноты связи порядковых признаков. В результате были получены взаимосвязи между шкалами «Динамичность нервных процессов» положительно коррелирует со шкалами: «Реалистичный тип» $\left(0,71\right.$ при $\left.r^{*} \geq 0,5\right)$; «Интеллектуальный тип» $\left(0,64\right.$ при $\left.r^{*} \geq 0,5\right)$; «Социальный тип» $\left(0,68\right.$ при $\left.r^{*} \geq 0,5\right)$; «Конвенциальный тип» $\left(0,63\right.$ при $\left.r^{*} \geq 0,5\right)$, «Артистичный тип» $\left(0,61\right.$ при $\left.r^{*} \geq 0,5\right)$.

Выводы. Исследуя взаимосвязь между особенностями темперамента и профессиональной направленностью личности у курсантов образовательных учреждений войск национальной гвардии РФ, мы сделали ряд выводов:

1. Имеется связь высокого уровня возбуждения и динамичности нервных процессов с артистическим типом профессиональной направленности.

2. Курсанты, у которых была обнаружена средняя или высокая степень уравновешенности лично- сти, проявляли предрасположенность к профессиональной направленности социального типа. Кроме того, было установлено, что респонденты, у которых выявлен высокий уровень переключаемости между различными типами деятельности, аналогично демонстрируют предрасположенность к социальной деятельности.

3. Прослеживается взаимосвязь между предрасположенностью к предприимчивому типу профессиональной направленности и силой, присущей процессам возбуждения. Так, у респондентов, проявляющих предрасположенность к деятельности, требующей наличия лидерских качеств и креативного склада личности, были обнаружены процессы возбуждения и социальный темп высокого уровня.

4. У исследуемых, чьи процессы торможения протекают на среднем и высоком уровне, был выявлен конвенциальный тип личности.

5. Преобладающему большинству исследуемых присущи умеренные эмоциональные реакции, уравновешенное настроение, спокойное поведение, терпение, хладнокровие, адекватная оценка собственных сил и возможностей.

\section{ЛИТЕРАТУРА}

1. Айзенк, Г.Ю. Структура личности / Г.Ю. Айзенк.- СПб.: Ювента.- Москва: КСП+.-1999.- 334 с.

2. Зеер, Э.Ф. Психология профессий / Э.Ф. Зеер.- Учебное пособие. - Академический проект Фонд «Мир».- 2006-236 с.

3. Зеер, Э.Ф. Психология профессионального самоопределения в ранней юности / Э.Ф. Зеер. - МПСИ.- 2008.-344 с.

4. Зеер, Э.Ф. Психология профессиональных деструкций / Э.Ф. Зеер. - Москва: Деловая книга.- 2013. - 240 с.

5. Климов, Е.А. Психология профессионального самоопределения: учеб. пособие для студентов вузов, обучающихся по специальностям: Педагогика и психология, Соц. педагогика, Педагогика / Е.А. Климов. - Москва: Academia, 2009. - 301 c.

6. Небылицын, В.Д. Темперамент // Психология индивидуальных различий: учебное пособие / Под ред. Ю.Б. Гиппенрейтер, В.Я. Романова. - М.: ЧеРо, 2000. - C. 352-359

7. Петровский, А.В. Общая психология. Учебник для педагогических вузов / А.В. Петровский, М.Г. Ярошевский. - Москва: Академия, 2009. - 501 с.

8. Пырьев, Е.А. Психология труда: учебное пособие / Е.А. Пырьев — М. : «Центральный коллектор библиотек «БИБКОМ», 2013.- 321 с.

9. Русалов В.М. Темперамент в структуре индивидуальности человека. Дифференциально-психофизиологические и психологические исследования / Русалов В.М. - Москва: Институт психологии РАН, 2012. - 528 с.

10. Стреляу, Я. Роль темперамента в психическом развитии / Я. Стреляу. - М.: Прогресс, 1982. - 232 с. 